\title{
Role of HMG-CoA reductase inhibitors with curative radiotherapy in men with prostate cancer
}

\author{
This article was published in the following Dove Press journal: \\ Open Access Journal of Urology \\ 14 June 201 I \\ Number of times this article has been viewed
}

\section{Abhishek A Solanki \\ Stanley L Liauw}

Department of Radiation and Cellular Oncology, University of Chicago

Medical Center, Chicago, IL, USA
Correspondence: Stanley L Liauw

5758 South Maryland Avenue, MC 9006 ,

Chicago, IL 60637, USA

Tel + I 7737026870

Fax +I 7738347340

Emailsliauw@radonc.uchicago.edu

\begin{abstract}
Brachytherapy and external beam radiotherapy are effective and commonly used treatment modalities in men with localized prostate cancer. In this review, we explore the role of radiation therapy in the curative management of prostate cancer, including the use of conformal therapeutic techniques to allow for the escalation of radiation doses to tumor, along with the use of combined radiation and hormonal therapy to enhance disease outcomes in men with aggressive disease. We also review the possible anticancer role of HMG-CoA reductase inhibiting agents (statins) in men with prostate cancer. Laboratory evidence suggests that statins may have antineoplastic effects when used alone and may sensitize cells to radiation therapy when given in combination. We explore the biologic basis for an anticancer effect and the clinical evidence suggesting statins may aid in improving outcomes with radiation therapy for localized prostate cancer.
\end{abstract}

Keywords: HMG-CoA reductase inhibitors, statins, radiotherapy, prostate cancer

\section{Introduction}

Prostate cancer is the most commonly diagnosed malignancy in elderly men. Approximately 217,730 patients in the USA are estimated to have been diagnosed with prostate cancer in 2010, and 32,050 will die of the disease. ${ }^{1}$ The optimal management of prostate cancer is nuanced and specific to any given patient's clinical presentation, comorbid medical conditions, and predicted disease course. Active surveillance, radical prostatectomy, and radiotherapy (including external beam radiotherapy [EBRT] and brachytherapy), are the primary management options for localized prostate cancer. Since the implementation of widespread prostate-specific antigen (PSA) screening, there has been a shift in the pattern of initial presentation in men diagnosed with prostate cancer. Over the last 30 years, there has been a shift from clinically palpable disease on digital rectal examination toward diagnosis via screening PSA elevation in nearly $50 \%$ of patients. ${ }^{2}$ With this in mind, the key consideration in the approach to the patient with newly diagnosed prostate cancer involves the estimation of whether a cancer may create clinically significant morbidity and mortality. Multiple parameters have been used to help differentiate those who may have clinically significant disease and may benefit from aggressive local therapy. These include the presence of a palpable nodule on digital rectal examination, Gleason score on biopsy, pretreatment PSA, and the percentage of biopsy cores which contain disease. These factors are used to categorize patients as having low-risk, intermediate-risk, or high-risk disease, and consequently help guide decision-making. ${ }^{3-8}$ In this review, we aim to introduce the radiotherapeutic issues in the treatment of localized prostate cancer, and present the biologic rationale 
and clinical data for the possible anticancer effect of HMG$\mathrm{CoA}$ reductase inhibitors (statins) with radiotherapy in the treatment of prostate cancer.

\section{Local therapy for prostate cancer}

In men undergoing treatment for prostate cancer, there are few randomized studies comparing the different treatment modalities, and no clearly superior treatment exists. ${ }^{9-12}$ Thus the decision for surgery or radiotherapy is influenced by patient comorbidity, age, a tolerable side effect profile, and patient preference. ${ }^{13}$ Retrospective data suggest that both treatment modalities offer similar biochemical control. A retrospective analysis of 1682 men with cT1-2 disease treated at the Cleveland Clinic with prostatectomy or high-dose EBRT revealed similar biochemical control in both cohorts with long-term follow-up. ${ }^{14}$ Potters et al performed a retrospective study of 1819 patients with cT1-2 disease treated with either radical prostatectomy, EBRT, or seed implant, and also showed similar freedom from biochemical recurrence at seven years, with $74 \%$ (seed implant), $77 \%$ (EBRT), and $79 \%$ (radical prostatectomy) for the three groups $(P=0.09) .{ }^{15}$ Nearly $40 \%$ of men with prostate cancer ultimately pursue radiotherapeutic modalities for treatment. ${ }^{16}$

\section{Radiation therapy for prostate cancer}

Radiotherapy is used in the curative treatment of multiple malignancies, and can also play an important role in palliation. EBRT uses X-rays created by a linear accelerator to damage the DNA of malignant cells. This is accomplished via direct damage to DNA strands as well as by the creation of oxygen radicals, which contribute a relatively larger proportion of the damage to DNA. Although X-ray radiation is not cell-specific, its greatest impact is in rapidly dividing cells, because the damage to DNA manifests in apoptosis and senescence during cellular mitosis/meiosis. Actively dividing normal tissue cells are also at risk for damage from radiotherapy, leading to the toxicities of treatment. In men undergoing radiotherapy for prostate cancer, the rectum and bladder are the primary normal tissues at risk for radiation damage. Thus, the most successful delivery of radiation necessitates a balance between acute and long-term toxicity to normal tissues and maximal tumor cell kill. Small daily doses of radiotherapy (fractionation) over several sessions (eg, 8-9 weeks for prostate cancer) are frequently prescribed to take advantage of the differential sensitivity of normal tissues and malignant cells to radiotherapy. Advances in planning (intensity-modulated radiotherapy) and onboard imaging have significantly improved the ability to deliver high doses of radiation therapy safely, resulting in improved cure rates. Alternatively, agents that sensitize tissues to radiation damage (radiosensitizing agents) can also contribute to increased cell kill, and could widen the therapeutic window by increasing the lethality of radiotherapeutic effects.

\section{EBRT dose escalation}

In men who select EBRT, there is evidence to indicate that doses greater than 70 Gy provide improved prostate cancer control. Multiple randomized trials have demonstrated the benefit of dose escalation in the definitive management of prostate cancer. Pollack et al randomized 301 men with cT1-T3 disease to 70 Gy and 78 Gy. ${ }^{17,18}$ Ten-year freedom from biochemical or clinical failure was $73 \%$ in the 78 Gy group and $50 \%$ in the 70 Gy group $(P=0.004)$. A Dutch randomized study by Peeters et al also showed a benefit in biochemical or clinical progression-free survival with 78 Gy over 68 Gy in 664 men. ${ }^{19,20}$ Seven-year freedom from failure was $56 \%$ for 78 Gy and $45 \%$ for 68 Gy. Zietman et al randomized 393 men with cT1b-T2b disease to 70.2 Gy or 79.2 Gy using combined photon and proton EBRT. $^{21,22}$ Those receiving 79.2 Gy had significantly improved ten-year biochemical progression-free survival ( $83 \%$ versus $68 \%$ ). The Medical Research Council assessed whether the benefit of dose escalation was maintained with the use of neoadjuvant and concurrent hormonal therapy. The Medical Research Council RT01 trial randomized men with T1b-T3a disease to 3-5 months of neoadjuvant and concurrent hormonal therapy with either 64 Gy or $74 \mathrm{~Gy}{ }^{23}$ Five-year biochemical progression-free survival was $71 \%$ in the dose-escalated group and $60 \%$ for the lower-dose group (hazard ratio [HR] 0.67 [0.53-0.85], $P=0.007$ ). There was a trend toward improved clinical progression-free survival and freedom from salvage androgen suppression therapy. ${ }^{23}$

\section{Brachytherapy}

Radioactive seed implant (brachytherapy) is an effective and convenient alternative to traditional EBRT, and can provide similar outcomes when performed properly. In this procedure, seeds formed of a radioactive isotope, commonly iodine- 125 or palladium-103, are placed within the prostate gland. These seeds emit high-energy gamma irradiation over a small distance, allowing for a very conformal treatment modality. Patients electing for brachytherapy undergo a volume study to plan an optimal seed arrangement to deliver a tumoricidal dose to the prostate, while limiting excessively high doses to the urethra. The implant procedure is usually performed over 
1-2 hours on an outpatient basis. Candidacy for brachytherapy is based on prostate volume, disease risk category, history of transurethral resection of the prostate, and ability to tolerate spinal or general anesthesia. Prostate volumes smaller than 15-20 $\mathrm{mL}$ may have an increased radiation dose to the urethra. Additionally, seed implantation in men with gland volumes greater than $60 \mathrm{~mL}$ may be technically difficult or even impossible due to pubic arch interference, making these groups poor candidates. Brachytherapy as monotherapy is used mostly in those with low-risk disease, although combined EBRT and brachytherapy has been shown to provide disease control in higher-risk patients. ${ }^{24,25}$ Radiation dosimetry appears to be a key factor in biochemical control. Stock et al found that doses greater than 140 Gy to $90 \%$ of the prostate volume allowed for $96 \%$ six-year freedom from biochemical failure compared with $60 \%$ in those with lower doses. ${ }^{26}$

\section{Radiotherapy + hormonal therapy}

Hormonal therapy with gonadotropin-releasing hormonal agents and nonsteroidal antiandrogens has been shown to be an effective, although ultimately temporary, single-treatment modality in prostate cancer. ${ }^{27}$ One proposed mechanism of hormonal therapy is likely via apoptosis of prostate cancer cells. ${ }^{28}$ Hormonal therapy has been found to have an additive, and possibly synergistic, effect with radiotherapy on malignant cells in both in vitro and animal studies. ${ }^{29-31}$ This has led to the study of hormonal therapy with radiation to sensitize prostate cancer cells to radiotherapy, allowing for increased cell kill with a similar radiation dose.

The role of combined radiotherapy and neoadjuvant, concurrent, and adjuvant androgen suppression therapy in men with more aggressive prostate cancer has been studied in multiple randomized studies. ${ }^{32-43}$ In patients with high-risk disease, there appears to be a benefit to long-term androgen suppression therapy; men in this cohort often receive 2-3 years of hormonal therapy with radiation therapy. ${ }^{35-43}$ In intermediate-risk patients, randomized studies suggest a benefit for shorter-term androgen suppression. ${ }^{32-34}$ These men typically receive six months of hormonal therapy with radiation therapy. Among those with intermediate-risk disease, men with percent positive cores greater than $50 \%$ may benefit more than those with lower volume disease. ${ }^{7}$ However, the benefit of hormonal therapy must be weighed against the potential toxicity, including increased risk of cardiovascular events, metabolic syndrome, hot flashes, and decreased libido and sexual function. ${ }^{44}$ Thus, those with significant medical comorbidity may not be optimal candidates for treatment, and selection of those who would most benefit from hormonal therapy becomes a more difficult question.

\section{Statins as anticancer agents}

Despite advances in technique and technology in both brachytherapy and EBRT, there continues to be a challenge to provide excellent rates of disease control while keeping the risk of toxicity very low. There is growing evidence that HMG-CoA reductase inhibitors (statins) may have a role in patients with prostate cancer. We surveyed the literature regarding the use of statins as anticancer agents using the search phrases "statin + radiotherapy," "statin + prostate cancer," and "statin + cancer" via PubMed, the American Society of Therapeutic Radiology and Oncology abstract database, and the American Society of Clinical Oncology abstract database.

Although the effect of statins in overall prostate cancer incidence is unclear, statin users may have a decreased risk of advanced prostate cancer. ${ }^{45-47}$ Shannon et al performed a case-control study evaluating the association between statins and risk of prostate cancer, and found a reduction in risk of development of Gleason score $\geq 7$ disease. ${ }^{47}$ Murtola et al similarly found no benefit for overall prostate cancer incidence, but a decreased risk for advanced disease in a nonPSA-screened population in Finland. ${ }^{48}$ Platz et al performed a study in a large cohort of health professionals, and found a decreased risk of metastatic and fatal prostate cancer, but no association with total prostate cancer incidence. ${ }^{45}$

In addition to the hypothesized preventative benefit of statin use, laboratory studies suggest that statins may also have anticancer activity. This opens up the possibility to use statin agents in the treatment of malignancy. Below we discuss the biologic evidence suggesting an anticancer effect of statin agents, as well as clinical studies evaluating the relationship between statin agents and biochemical and clinical outcomes in prostate cancer.

\section{Statins as radiosensitizing agents}

Considerable effort has been made to understand the effects of statins on malignancy at the cellular level. HMG-CoA reductase inhibitors have been hypothesized to have antineoplastic activity through several mechanisms, including decreasing tissue inflammation, antiangiogenesis, decreased tumor cell adhesion/invasion, and increasing tumor cell apoptosis. ${ }^{49-57}$ Specifically, in prostate cancer, Zhuang et al showed that simvastatin may increase apoptosis in certain prostate cancer cells by modulating membrane lipids. ${ }^{58}$ Multiple studies have implicated possible cellular signaling 
pathways involved in anticancer activity. ${ }^{59,60}$ However, in most of these studies, statins have only been shown to exert significant anticancer activity at high doses.

The evaluation of statins to potentiate other established antineoplastic therapeutic modalities, such as radiotherapy, may yield more implications for clinical management. In prostate cancer, several laboratory studies have evaluated the ability of statin agents to act as radiosensitizing agents, ie, to make tumor cells more sensitive to radiotherapy. However, the data suggest that statins may have a more complex relationship with radiotherapy than being mere sensitizers. Nubel et al found that lovastatin and simvastatin decreased E-selectin gene activation in human umbilical vein endothelial cells and EA.hy-926 cells treated with radiation. ${ }^{53} \mathrm{E}$-selectin has been shown to increase tumor cell adhesion to endothelial cells, thus facilitating extravasation, and potentially promoting metastasis. ${ }^{61}$ Thus by modulating E-selectin gene activation, lovastatin may play a role in decreasing the likelihood of tumor spread. ${ }^{62}$ It may do so through inhibition of nuclear factor kappa beta activation, which is necessary for E-selectin expression. However, this only seems to hold true at high doses. Nubel et al found that at lower doses, lovastatin may decrease apoptosis in human umbilical vein endothelial cells undergoing radiation, thus suggesting a radioprotective effect in endothelial cells. ${ }^{63}$ Seemingly, at lower doses (closer to physiologic intracellular and intravascular doses), statins may have a radioprotective effect, while at higher doses $(>10 \mu \mathrm{mol} / \mathrm{L})$, they may have a radiosensitizing effect. Since many of the toxic side effects of radiotherapy have their roots in endothelial dysfunction, improving endothelial stability could potentially allow for more tolerable toxicity profiles, leading to closer adherence to therapy and reduced late toxicity. ${ }^{64-66}$

Fritz et a ${ }^{67}$ studied the effect of pretreatment with lovastatin on cellular apoptosis and cytotoxicity after radiation with gamma rays in multiple human cancer cell lines, and found that lovastatin acted as a radiosensitizer in a cellspecific and dose-dependent manner. In this study, while sensitizing HeLa cervical cancer and MeWo human melanoma cell lines, there was no effect on DLD1 colon cancer, T47D and MCF-7 breast cancer, and Chinese hamster ovary $\mathrm{K} 1$ cell lines. Specifically, lovastatin pretreatment in HeLa cells was not associated with changes in double-strand DNA breaks or subsequent repair, but did appear to decrease the fraction of cells in the $\mathrm{G} 2$ phase of the cellular cycle from $50 \%$ to $25 \%$ at $24-72$ hours after radiation. ${ }^{67}$ Because increases in cellular G2 arrest following radiation have been associated with increased resistance to radiation, ${ }^{68-70}$ the authors suggested that the radiosensitizing effects of lovastatin may be at least in part due to this phenomenon. ${ }^{67}$ Additionally, statins have been found to be radiosensitizers by decreasing isoprenylation of the oncogenes, ras and rho, in cells with increased activity of the ras oncogene, which is important in patients undergoing radiation therapy, because increased ras activity has also been associated with radiation resistance. ${ }^{71,72}$

\section{Statin use and outcomes with radiotherapy}

To assess the clinical significance of these laboratory studies, several groups have investigated the effect of combined statin use with radiotherapy. In addition to the prevention of aggressive prostate cancer, statins may play a role in the treatment of other malignancies. For example, in a cohort of patients treated with preoperative concurrent chemoradiotherapy for rectal carcinoma, statin use was associated with an improved pathologic complete response at the time of surgery. ${ }^{73}$

In men with prostate cancer, the results of retrospective studies in men undergoing EBRT and/or brachytherapy show inconsistent changes in biochemical, survival, and clinical progression in statin users. Table 1 depicts the results of several recent studies comparing outcomes after radiotherapy in statin users and statin nonusers undergoing treatment for prostate cancer.

\section{Statin use and biochemical control}

Moyad et al studied a cohort of 512 patients with cT1-T3a localized disease undergoing brachytherapy, of whom 65 were statin users. ${ }^{74}$ With a median follow-up of 5.3 years, eight-year biochemical progression-free survival, defined as $\mathrm{PSA} \leq 0.4 \mathrm{ng} / \mathrm{mL}$, was higher in statin users, although this difference was not statistically significant ( $97 \%$ versus $94 \%$, $P=0.398)$. However, statin users in this study had a more favorable clinical presentation. This group had significantly more T1b-T2b stage patients ( $92 \%$ versus $77 \%, P=0.006$ ), lower pretreatment PSA (median 5.7 versus 6.9, $P=0.012$ ), and a shorter follow-up (median 4.4 versus 5.5 years, $P=0.002$ ). When divided into risk subgroups, no subset had a statisically significant improvement in progressionfree survival. Multivariate analysis of the data showed that statin use was not a significant predictor of biochemical progression-free survival. ${ }^{74}$

In a follow-up study, Moyad et al published nine-year outcomes data of an expanded cohort of 938 patients, with 191 statin users. ${ }^{75}$ Although length of follow-up, pretreatment 


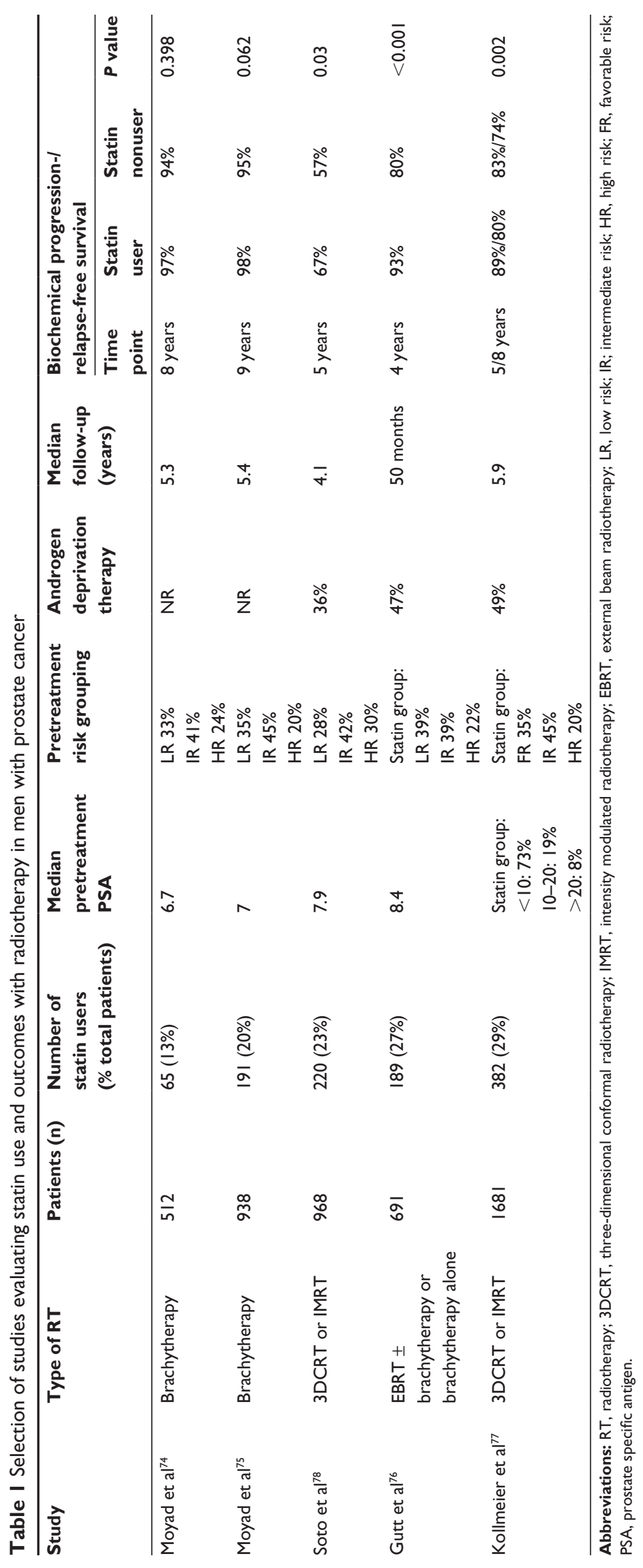


PSA, prostate volume, and percent positive biopsies were still statistically more favorable in statin users, nine-year biochemical progression-free survival trended to be better in statin users. Despite this, statin use was not significantly associated with improved biochemical outcome on multivariate analysis. ${ }^{75}$

Gutt et $\mathrm{al}^{76}$ studied 691 men with prostate cancer, of whom $61(9 \%)$ had brachytherapy only, $584(84 \%)$ men had EBRT, and 46 men had a combination of the two (7\%). Forty-one percent of the men received neoadjuvant, concurrent, or adjuvant androgen deprivation therapy (ADT), with a median duration of four months. In this cohort, 189 men were statin users $(27 \%)$. With a median follow-up of 50 months, fouryear freedom from biochemical failure was $93 \%$ in statin users, compared with $80 \%$ in statin nonusers. This benefit was seen in all National Comprehensive Cancer Network risk groups, and was independent of hormonal use and radiotherapy dose. Additionally, statin dose and type of statin did not impact freedom from biochemical failure. Statin use was associated with freedom from biochemical failure, as well as relapse-free survival, on both univariate and multivariate analysis (HR 0.43 for freedom from biochemical failure, $95 \%$ confidence interval $0.25-0.73) .{ }^{76}$ A subset analysis of men with lipid panels available $(n=293)$ at the start of radiation therapy demonstrated that men with lower low-density lipoprotein levels also had improved outcome, independent of statin use. Although the numbers of patients in this subset analysis were too limited to make firm conclusions, the results suggest that the potential anticancer effect of statins may be, at least in part, mediated through the lipid pathway.

Kollmeier et al performed a retrospective review of 1681 men with prostate cancer undergoing EBRT. ${ }^{77}$ Fiftysix percent of men received neoadjuvant and concurrent hormonal therapy. In total, 382 men (23\%) were statin users. With a median follow-up of 5.9 years, statin users had an improved eight-year PSA relapse-free survival compared with nonusers. Eight-year PSA relapse-free survival was $80 \%$ in statin users, and $74 \%$ in nonusers $(P=0.002)$. Univariate and multivariate analysis revealed statin use was associated with improved PSA relapse-free survival. Analysis by National Comprehensive Cancer Network risk category revealed that this association was limited to men in the highrisk group. Men with high-risk prostate cancer had eight-year PSA relapse-free survival of $75 \%$ in men treated with a statin, compared with $58 \%$ in men not on a statin. ${ }^{77}$

Conversely, Soto et al found that statin use did not correlate with differences in biochemical failure in a cohort of 968 patients undergoing EBRT. Although statin users had better 5-year progression-free survival (67\% versus
$57 \%$ ) on univariate analysis, when limiting the cohort to patients treated during 1996-2006, statin users failed to have improved biochemical progression-free survival on multivariate analysis, because the statin group had fewer high-risk patients than the nonstatin group. ${ }^{78}$ Sharma et al reviewed 983 patients receiving EBRT in a cohort of men with mostly T1-T2 stage disease, excluding those having ADT prior to radiation therapy, and compared outcomes with respect to statin use. ${ }^{79}$ With a median follow-up of 58.1 months, there was no difference in biochemical progression-free survival among statin users and statin nonusers. ${ }^{79}$

Interestingly, statin use has been correlated with improved rates of biochemical control in men undergoing radical prostatectomy. Hamilton et al studied 1319 men treated with radical prostatectomy at four Veterans Administration hospitals with clinical data available in the SEARCH (Shared Equal Access Regional Cancer Hospital) database. ${ }^{80}$ At the time of prostatectomy, 236 men (18\%) were statin users. Statin use was documented and dose was normalized to an equivalent dose. A total of 260 men (20\%) received radiation therapy, $158(12 \%)$ received hormonal therapy, and $84(6 \%)$ received both following surgery. There was no significant difference in adjuvant treatment between statin users and nonusers. After controlling for multiple clinical and pathologic factors, statin use was associated with a decreased risk of PSA recurrence (HR $0.70, P=0.03$ ). This held true only in men with a statin dose of at least one dose equivalent ( $46 \%$ reduced risk of biochemical recurrence). Duration of statin use prior to surgery was not associated with biochemical outcome. ${ }^{80}$

\section{Statin use and clinical endpoints}

Changes in survival outcomes in statin users undergoing radiotherapy have been evaluated in several studies. Moyad et al found that statin users undergoing brachytherapy for prostate cancer trended toward better nine-year overall survival and cancer-specific survival. ${ }^{75}$ In this study, atorvastatin users had a trend for improved overall survival compared with men taking other statin drugs (94\% versus $81.3 \%, P=0.12$ ). Additionally, patients being treated with ADT who were statin users trended toward better cancer-specific survival, overall survival, and biochemical progression-free survival than statin nonusers. ${ }^{75}$ Participants in the CaPSURE trial undergoing statin therapy did not have any improved prostate cancer-specific mortality. ${ }^{81}$ Gutt et al, Sharma et al, and Kollmeier et al found no statistically significant difference in cancer-specific survival or overall survival between statin users and statin nonusers. ${ }^{76,77,79}$ Additionally, no difference in the development of metastatic 
disease was found, although follow-up duration may not have been long enough to detect any such difference in all of these studies. ${ }^{76,77,79}$

One of the challenges in interpreting the results of many of these studies is that statin users tend to present with more favorable prognostic factors, such as Gleason score and pretreatment PSA, as well as differences in radiation treatment parameters. In retrospective cohort studies it is unclear how much of this imbalance in disease presentation is attributable to more aggressive PSA screening and earlier presentation by nature of more health-conscious patients. Comparative analysis becomes even more complex when patients undergo multiple treatment modalities such as ADT in addition to EBRT, because most radiation therapy studies had some proportion of patients undergoing ADT. Additionally, it is unclear whether the statins are merely suppressing PSA values or actually suppressing disease growth, because statins have been shown to decrease PSA levels in healthy individuals. ${ }^{82,83}$ The effect of cholesterol levels and obesity on prostate cancer has also been controversial, and may obscure the true benefit of statins in these studies. ${ }^{58,84,85}$ As noted earlier, Gutt et al had pretreatment lipid panel information available for a subset of men. Pretreatment high-density lipoprotein and triglyceride levels were not associated with improved freedom from biochemical progression (FFBP) but lower total cholesterol and low-density lipoprotein values were correlated with improved FFBP. ${ }^{76}$

\section{Statin tolerability}

Overall, statin agents have a relatively low risk of significant adverse reactions. The two most common dangerous side effects are hepatic dysfunction and myopathy. A metaanalysis of 35 randomized trials (74,102 subjects) found a significantly increased risk of transaminase elevation of 4.2 cases per 1000 versus placebo. There was no significant increase in the risk of myalgia, creatine kinase elevation, or rhabdomyolysis. However, older patients, those with renal insufficiency or chronic active disease, and those using combined therapy are often excluded in these trials. ${ }^{86} \mathrm{~A}$ study of 23,000 patients in a large health maintenance organization found that statin users had a $0.1 \%$ rate of developing alanine aminotransferase elevation higher than 10 times the upper limit of normal, with most of these due to drug interactions. In nearly all these cases, elevation resolved upon discontinuation of the statin agent. ${ }^{87,88}$

The presentation of myopathy in statin users encompasses a spectrum from myalgias to rhabdomyolysis that could potentially result in renal damage. The incidence of overall myopathy is 1.2 per 10,000 person-years in statin users, which is similar to that in the general population. ${ }^{87}$ The incidence of rhabdomyolysis was $0.05 \%$ in patients receiving simvastatin in the Heart Protection Study. ${ }^{89,90}$ Although randomized data fail to show significantly increased risks for myopathy, it continues to be a common cause for discontinuation of statin therapy in clinics.

Other complications of statin use have not clearly been elucidated. There may be a small increase in the risk for diabetes in patients using statins. A meta-analysis of 13 trials found a small increase in risk for diabetes (odds ratio 1.09). ${ }^{91,92}$ Additionally, benign proteinuria has also been seen in statin users. ${ }^{92,93}$ Meanwhile, the association of statin use with an increased risk for cataracts, neuropathy, and memory loss has been suggested, but remains unclear. ${ }^{94-99}$

\section{Conclusion}

Although the results of several studies investigating the role of statins in improving the outcomes of radiotherapy in men with prostate cancer are encouraging, it is difficult to draw firm conclusions regarding the efficacy of statins to improve cancer control. Without a randomized prospective study testing the biochemical and clinical outcomes in men with prostate cancer treated with radiotherapy with or without statin therapy, the exact impact of statin use cannot be assessed. Additionally, the optimal dose and timing of statin administration is unclear. Due to the retrospective nature of the existing data, the relatively short follow-up, and heterogeneous populations in these studies, we cannot make a clear judgment regarding the efficacy of statins in addition to radiotherapy in men with prostate cancer. However, the possibility exists for these relatively safe and inexpensive agents to augment radiotherapy outcomes to have a potential impact on improving prostate cancer cure rates, and to decrease the need for relatively toxic adjuvant therapies, such as hormonal therapy. Further dose escalation of statin therapy, and ultimately a randomized controlled trial, would be warranted to elucidate the optimal role of statins in the treatment of prostate cancer.

\section{Disclosure}

The authors report no conflicts of interest in this work.

\section{References}

1. Jemal A, Siegel R, Xu J, Ward E. Cancer statistics, 2010. CA Cancer J Clin. 2010;60:277-300.

2. Cooperberg MR, Lubeck DP, Meng MV, Mehta SS, Carroll PR. The changing face of low-risk prostate cancer: trends in clinical presentation and primary management. J Clin Oncol. 2004;22:2141-2149. 
3. Roach M, Lu J, Pilepich MV, et al. Four prognostic groups predict long-term survival from prostate cancer following radiotherapy alone on Radiation Therapy Oncology Group clinical trials. Int J Radiat Oncol Biol Phys. 2000;47:609-615.

4. Roach M 3rd, Marquez C, Yuo HS, et al. Predicting the risk of lymph node involvement using the pre-treatment prostate specific antigen and Gleason score in men with clinically localized prostate cancer. Int J Radiat Oncol Biol Phys. 1994;28:33-37.

5. Makarov DV, Trock BJ, Humphreys EB, et al. Updated nomogram to predict pathologic stage of prostate cancer given prostate-specific antigen level, clinical stage, and biopsy Gleason score (Partin tables) based on cases from 2000 to 2005. Urology. 2007;69:1095-1101.

6. D'Amico AV, Whittington R, Malkowicz SB, et al. Biochemical outcome after radical prostatectomy, external beam radiation therapy, or interstitial radiation therapy for clinically localized prostate cancer. JAMA. 1998;280:969-974.

7. D'Amico AV, Renshaw AA, Cote K, et al. Impact of the percentage of positive prostate cores on prostate cancer-specific mortality for patients with low or favorable intermediate-risk disease. J Clin Oncol. 2004;22:3726-3732.

8. Scardino P. Update: NCCN prostate cancer clinical practice guidelines. J Natl Compr Canc Netw. 2005;3 Suppl 1:S29-S33.

9. Wilt TJ, Brawer MK, Barry MJ, et al. The Prostate cancer Intervention Versus Observation Trial: VA/NCI/AHRQ Cooperative Studies Program \#407 (PIVOT): design and baseline results of a randomized controlled trial comparing radical prostatectomy to watchful waiting for men with clinically localized prostate cancer. Contemp Clin Trials. 2009;30:81-87.

10. Cooperberg MR, Vickers AJ, Broering JM, Carroll PR. Comparative risk-adjusted mortality outcomes after primary surgery, radiotherapy, or androgen-deprivation therapy for localized prostate cancer. Cancer. 2010;116:5226-5234.

11. PRO6 Collaborators. Early closure of a randomized controlled trial of three treatment approaches to early localised prostate cancer: the MRC PR06 trial. BJU Int. 2004;94:1400-1401.

12. Paulson DF, Lin GH, Hinshaw W, Stephani S. Radical surgery versus radiotherapy for adenocarcinoma of the prostate. J Urol. 1982;128: 502-504.

13. Sanda MG, Dunn RL, Michalski J, et al. Quality of life and satisfaction with outcome among prostate-cancer survivors. N Engl J Med. 2008; 358:1250-1261.

14. Kupelian PA, Elshaikh M, Reddy CA, Zippe C, Klein EA. Comparison of the efficacy of local therapies for localized prostate cancer in the prostate-specific antigen era: a large single-institution experience with radical prostatectomy and external-beam radiotherapy. J Clin Oncol. 2002;20:3376-3385.

15. Potters L, Klein EA, Kattan MW, et al. Monotherapy for stage T1-T2 prostate cancer: radical prostatectomy, external beam radiotherapy, or permanent seed implantation. Radiother Oncol. 2004;71:29-33.

16. Hamilton AS, Albertsen PC, Johnson TK, et al. Trends in the treatment of localized prostate cancer using supplemented cancer registry data. BJU Int. 2011;107:576-584.

17. Pollack A, Zagars GK, Starkschall G, et al. Prostate cancer radiation dose response: results of the M.D. Anderson phase III randomized trial. Int J Radiat Oncol Biol Phys. 2002;53:1097-1105.

18. Kuban DA, Tucker SL, Dong L, et al. Long-term results of the M.D. Anderson randomized dose-escalation trial for prostate cancer. Int J Radiat Oncol Biol Phys. 2008;70:67-74.

19. Peeters ST, Heemsbergen WD, Koper PC, et al. Dose-response in radiotherapy for localized prostate cancer: results of the Dutch multicenter randomized phase III trial comparing 68 Gy of radiotherapy with 78 Gy. J Clin Oncol. 2006;24:1990-1996.

20. Al-Mamgani A, van Putten WL, van der Wielen GJ, Levendag PC, Incrocci L. Dose escalation and quality of life in patients with localized prostate cancer treated with radiotherapy: long-term results of the Dutch randomized dose-escalation trial (CKTO 96-10 Trial). Int $J$ Radiat Oncol Biol Phys. 2011;79:1004-1012.
21. Zietman AL, DeSilvio ML, Slater JD, et al. Comparison of conventional-dose vs high-dose conformal radiation therapy in clinically localized adenocarcinoma of the prostate: a randomized controlled trial. JAMA. 2005;294:1233-1239.

22. Zietman AL, Bae K, Slater JD, et al. Randomized trial comparing conventional-dose with high-dose conformal radiation therapy in earlystage adenocarcinoma of the prostate: long-term results from Proton Radiation Oncology Group/American College of Radiology 95-09. J Clin Oncol. 2010;28:1106-1111.

23. Dearnaley DP, Sydes MR, Graham JD, et al. Escalated-dose versus standard-dose conformal radiotherapy in prostate cancer: first results from the MRC RT01 randomised controlled trial. Lancet Oncol. 2007;8:475-487.

24. Grimm PD, Blasko JC, Sylvester JE, Meier RM, Cavanagh W. 10-year biochemical (prostate-specific antigen) control of prostate cancer with (125)I brachytherapy. Int J Radiat Oncol Biol Phys. 2001;51:31-40.

25. Merrick GS, Butler WM, Wallner KE, et al. Impact of supplemental external beam radiotherapy and/or androgen deprivation therapy on biochemical outcome after permanent prostate brachytherapy. Int J Radiat Oncol Biol Phys. 2005;61:32-43.

26. Stock RG, Stone NN, Tabert A, Iannuzzi C, DeWyngaert JK. A doseresponse study for I-125 prostate implants. Int J Radiat Oncol Biol Phys. 1998;41:101-108.

27. Lu-Yao GL, Albertsen PC, Moore DF, et al. Survival following primary androgen deprivation therapy among men with localized prostate cancer. JAMA. 2008;300:173-181.

28. Kyprianou N, English HF, Isaacs JT. Programmed cell death during regression of PC-82 human prostate cancer following androgen ablation. Cancer Res. 1990;50:3748-3753.

29. Zietman AL, Nakfoor BM, Prince EA, Gerweck LE. The effect of androgen deprivation and radiation therapy on an androgen-sensitive murine tumor: an in vitro and in vivo study. Cancer J Sci Am. 1997;3: $31-36$.

30. Joon DL, Hasegawa M, Sikes C, et al. Supraadditive apoptotic response of R3327-G rat prostate tumors to androgen ablation and radiation. Int J Radiat Oncol Biol Phys. 1997;38:1071-1077.

31. Pollack A, Ashoori F, Sikes C, et al. The early supra-additive apoptotic response of R3327-G prostate tumors to androgen ablation and radiation is not sustained with multiple fractions. Int J Radiat Oncol Biol Phys. 2000;46:153-158.

32. Denham JW, Steigler A, Lamb DS, et al. Short-term androgen deprivation and radiotherapy for locally advanced prostate cancer: results from the Trans-Tasman Radiation Oncology Group 96.01 randomised controlled trial. Lancet Oncol. 2005;6:841-850.

33. D'Amico AV, Manola J, Loffredo M, Renshaw AA, DellaCroce A, Kantoff PW. 6-month androgen suppression plus radiation therapy vs radiation therapy alone for patients with clinically localized prostate cancer: a randomized controlled trial. JAMA. 2004;292:821-827.

34. D'Amico AV, Chen MH, Renshaw AA, Loffredo M, Kantoff PW. Androgen suppression and radiation vs radiation alone for prostate cancer: a randomized trial. JAMA. 2008;299:289-295.

35. Pilepich MV, Winter K, Lawton CA, et al. Androgen suppression adjuvant to definitive radiotherapy in prostate carcinoma: long-term results of phase III RTOG 85-31. Int J Radiat Oncol Biol Phys. 2005;61: 1285-1290.

36. Pilepich MV, Winter K, John MJ, et al. Phase III radiation therapy oncology group (RTOG) trial 86-10 of androgen deprivation adjuvant to definitive radiotherapy in locally advanced carcinoma of the prostate. Int J Radiat Oncol Biol Phys. 2001;50:1243-1252.

37. Pilepich MV, Caplan R, Byhardt RW, et al. Phase III trial of androgen suppression using goserelin in unfavorable-prognosis carcinoma of the prostate treated with definitive radiotherapy: report of Radiation Therapy Oncology Group Protocol 85-31. J Clin Oncol. 1997;15:1013-1021.

38. Roach M 3rd, Bae K, Speight J, et al. Short-term neoadjuvant androgen deprivation therapy and external-beam radiotherapy for locally advanced prostate cancer: long-term results of RTOG 8610. J Clin Oncol. 2008;26:585-591. 
39. Bolla M, Collette L, Blank L, et al. Long-term results with immediate androgen suppression and external irradiation in patients with locally advanced prostate cancer (an EORTC study): a phase III randomised trial. Lancet. 2002;360:103-106.

40. Bolla M, Van Tienhoven G, Warde P, et al. External irradiation with or without long-term androgen suppression for prostate cancer with high metastatic risk: 10-year results of an EORTC randomised study. Lancet Oncol. 2010;11:1066-1073.

41. Lawton CA, Winter K, Murray K, et al. Updated results of the phase III Radiation Therapy Oncology Group (RTOG) trial 85-31 evaluating the potential benefit of androgen suppression following standard radiation therapy for unfavorable prognosis carcinoma of the prostate. Int J Radiat Oncol Biol Phys. 2001;49:937-946.

42. Hanks GE, Pajak TF, Porter A, et al. Phase III trial of long-term adjuvant androgen deprivation after neoadjuvant hormonal cytoreduction and radiotherapy in locally advanced carcinoma of the prostate: the Radiation Therapy Oncology Group Protocol 92-02. J Clin Oncol. 2003;21: 3972-3978.

43. Horwitz EM, Bae K, Hanks GE, et al. Ten-year follow-up of radiation therapy oncology group protocol 92-02: a phase III trial of the duration of elective androgen deprivation in locally advanced prostate cancer. J Clin Oncol. 2008;26:2497-2504.

44. D'Amico AV, Denham JW, Crook J, et al. Influence of androgen suppression therapy for prostate cancer on the frequency and timing of fatal myocardial infarctions. J Clin Oncol. 2007;25:2420-2425.

45. Platz EA, Leitzmann MF, Visvanathan K, et al. Statin drugs and risk of advanced prostate cancer. J Natl Cancer Inst. 2006;98:1819-1825.

46. Murtola TJ, Tammela TL, Lahtela J, Auvinen A. Cholesterol-lowering drugs and prostate cancer risk: a population-based case-control study. Cancer Epidemiol Biomarkers Prev. 2007;16:2226-2232.

47. Shannon J, Tewoderos S, Garzotto M, et al. Statins and prostate cancer risk: a case-control study. Am J Epidemiol. 2005;162:318-325.

48. Murtola TJ, Tammela TL, Maattanen L, et al. Prostate cancer and PSA among statin users in the Finnish prostate cancer screening trial. Int J Cancer. 2010;127:1650-1659.

49. Youssef S, Stuve O, Patarroyo JC, et al. The HMG-CoA reductase inhibitor, atorvastatin, promotes a Th2 bias and reverses paralysis in central nervous system autoimmune disease. Nature. 2002;420:78-84.

50. Hakamada-Taguchi R, Uehara Y, Kuribayashi K, et al. Inhibition of hydroxymethylglutaryl-coenzyme a reductase reduces Th1 development and promotes Th2 development. Circ Res. 2003;93:948-956.

51. Weis M, Heeschen C, Glassford AJ, Cooke JP. Statins have biphasic effects on angiogenesis. Circulation. 2002;105:739-745.

52. Rao S, Porter DC, Chen X, Herliczek T, Lowe M, Keyomarsi K. Lovastatin-mediated G1 arrest is through inhibition of the proteasome, independent of hydroxymethyl glutaryl-CoA reductase. Proc Natl Acad Sci U S A. 1999;96:7797-7802.

53. Nubel T, Dippold W, Kleinert H, Kaina B, Fritz G. Lovastatin inhibits Rho-regulated expression of E-selectin by TNFalpha and attenuates tumor cell adhesion. FASEB J. 2004;18:140-142.

54. Kusama T, Mukai M, Iwasaki T, et al. Inhibition of epidermal growth factor-induced RhoA translocation and invasion of human pancreatic cancer cells by 3-hydroxy-3-methylglutaryl-coenzyme a reductase inhibitors. Cancer Res. 2001;61:4885-4891.

55. Wu J, Wong WW, Khosravi F, Minden MD, Penn LZ. Blocking the Raf/MEK/ERK pathway sensitizes acute myelogenous leukemia cells to lovastatin-induced apoptosis. Cancer Res. 2004;64:6461-6468.

56. Shibata MA, Ito Y, Morimoto J, Otsuki Y. Lovastatin inhibits tumor growth and lung metastasis in mouse mammary carcinoma model: a p53-independent mitochondrial-mediated apoptotic mechanism. Carcinogenesis. 2004;25:1887-1898.

57. Wong WW, Tan MM, Xia Z, Dimitroulakos J, Minden MD, Penn LZ. Cerivastatin triggers tumor-specific apoptosis with higher efficacy than lovastatin. Clin Cancer Res. 2001;7:2067-2075.

58. Zhuang L, Kim J, Adam RM, Solomon KR, Freeman MR. Cholesterol targeting alters lipid raft composition and cell survival in prostate cancer cells and xenografts. J Clin Invest. 2005;115:959-968.
59. Graaf MR, Richel DJ, van Noorden CJ, Guchelaar HJ. Effects of statins and farnesyltransferase inhibitors on the development and progression of cancer. Cancer Treat Rev. 2004;30:609-641.

60. Weber MJ, Gioeli D. Ras signaling in prostate cancer progression. $J$ Cell Biochem. 2004;91:13-25.

61. Dimitroulakos J, Ye LY, Benzaquen M, et al. Differential sensitivity of various pediatric cancers and squamous cell carcinomas to lovastatininduced apoptosis: therapeutic implications. Clin Cancer Res. 2001;7: 158-167.

62. Nubel T, Dippold W, Kaina B, Fritz G. Ionizing radiation-induced E-selectin gene expression and tumor cell adhesion is inhibited by lovastatin and all-trans retinoic acid. Carcinogenesis. 2004;25: $1335-1344$.

63. Nubel T, Damrot J, Roos WP, Kaina B, Fritz G. Lovastatin protects human endothelial cells from killing by ionizing radiation without impairing induction and repair of DNA double-strand breaks. Clin Cancer Res. 2006;12:933-939.

64. Houchen CW, George RJ, Sturmoski MA, Cohn SM. FGF-2 enhances intestinal stem cell survival and its expression is induced after radiation injury. Am J Physiol. 1999;276:G249-G258.

65. Okunieff $P$, Mester $M$, Wang J, et al. In vivo radioprotective effects of angiogenic growth factors on the small bowel of $\mathrm{C} 3 \mathrm{H}$ mice. Radiat Res. 1998;150:204-211.

66. Santana P, Pena LA, Haimovitz-Friedman A, et al. Acid sphingomyelinase-deficient human lymphoblasts and mice are defective in radiation-induced apoptosis. Cell. 1996;86:189-199.

67. Fritz G, Brachetti C, Kaina B. Lovastatin causes sensitization of HeLa cells to ionizing radiation-induced apoptosis by the abrogation of G2 blockage. Int J Radiat Biol. 2003;79:601-610.

68. Theron T, Binder A, Verheye-Dua F, Bohm L. The role of G2-block abrogation, DNA double-strand break repair and apoptosis in the radiosensitization of melanoma and squamous cell carcinoma cell lines by pentoxifylline. Int J Radiat Biol. 2000;76:1197-1208.

69. Metting NF, Little JB. Transient failure to dephosphorylate the cdc2cyclin B1 complex accompanies radiation-induced G2-phase arrest in HeLa cells. Radiat Res. 1995;143:286-292.

70. Tamamoto T, Ohnishi K, Takahashi A, et al. Correlation between gamma-ray-induced G2 arrest and radioresistance in two human cancer cells. Int J Radiat Oncol Biol Phys. 1999;44:905-909.

71. Samid D, Miller AC, Rimoldi D, Gafner J, Clark EP. Increased radiation resistance in transformed and nontransformed cells with elevated ras proto-oncogene expression. Radiat Res. 1991;126:244-250.

72. Miller AC, Kariko K, Myers CE, Clark EP, Samid D. Increased radioresistance of EJras-transformed human osteosarcoma cells and its modulation by lovastatin, an inhibitor of p21ras isoprenylation. Int J Cancer. 1993;53:302-307.

73. Katz MS, Minsky BD, Saltz LB, Riedel E, Chessin DB, Guillem JG. Association of statin use with a pathologic complete response to neoadjuvant chemoradiation for rectal cancer. Int J Radiat Oncol Biol Phys 2005;62:1363-1370.

74. Moyad MA, Merrick GS, Butler WM, et al. Statins, especially atorvastatin, may favorably influence clinical presentation and biochemical progression-free survival after brachytherapy for clinically localized prostate cancer. Urology. 2005;66:1150-1154.

75. Moyad MA, Merrick GS, Butler WM, et al. Statins, especially atorvastatin, may improve survival following brachytherapy for clinically localized prostate cancer. Urol Nurs. 2006;26:298-303.

76. Gutt R, Tonlaar N, Kunnavakkam R, Karrison T, Weichselbaum RR, Liauw SL. Statin use and risk of prostate cancer recurrence in men treated with radiation therapy. J Clin Oncol. 2010;28:2653-2659.

77. Kollmeier MA, Katz MS, Mak K, et al. Improved biochemical outcomes with statin use in patients with high-risk localized prostate cancer treated with radiotherapy. Int J Radiat Oncol Biol Phys. 2011;79: $713-718$.

78. Soto DE, Daignault S, Sandler HM, Ray ME. No effect of statins on biochemical outcomes after radiotherapy for localized prostate cancer. Urology. 2009;73:158-162. 
79. Sharma NK, Ruth K, Horwitz E, Buyyounouski M, Pollack A. Statin use prior to radiation therapy for prostate cancer does not improve outcome: the Fox Chase experience. Int J Radiat Oncol Biol Phys. 2006;66:S366.

80. Hamilton RJ, Banez LL, Aronson WJ, et al. Statin medication use and the risk of biochemical recurrence after radical prostatectomy: results from the Shared Equal Access Regional Cancer Hospital (SEARCH) Database. Cancer. 2010;116:3389-3398.

81. Katz MS, D'Amigo AV, Cowan JE, Chan JM, Latini DM, Carroll PR. Association of statin and NSAID use and prostate cancer outcomes: results From CaPSURE. Int J Radiat Oncol Biol Phys. 2006;66:S338.

82. Cyrus-David MS, Weinberg A, Thompson T, Kadmon D. The effect of statins on serum prostate specific antigen levels in a cohort of airline pilots: a preliminary report. J Urol. 2005;173:1923-1925.

83. Hamilton RJ, Goldberg KC, Platz EA, Freedland SJ. The influence of statin medications on prostate-specific antigen levels. J Natl Cancer Inst. 2008;100:1511-1518.

84. Solomon KR, Freeman MR. Do the cholesterol-lowering properties of statins affect cancer risk? Trends Endocrinol Metab. 2008;19:113-121.

85. Freeman MR, Solomon KR. Cholesterol and prostate cancer. J Cell Biochem. 2004;91:54-69.

86. Kashani A, Phillips CO, Foody JM, et al. Risks associated with statin therapy: a systematic overview of randomized clinical trials. Circulation. 2006;114:2788-2797.

87. Rosenson RS. Current overview of statin-induced myopathy. Am J Med. 2004;116:408-416.

88. Charles EC, Olson KL, Sandhoff BG, McClure DL, Merenich JA. Evaluation of cases of severe statin-related transaminitis within a large health maintenance organization. Am J Med. 2005;118:618-624.

89. Gaist D, Rodriguez LA, Huerta C, Hallas J, Sindrup SH. Lipid-lowering drugs and risk of myopathy: a population-based follow-up study. Epidemiology. 2001;12:565-569.
90. Heart Protection Study Collaborative Group. MRC/BHF Heart Protection Study of cholesterol lowering with simvastatin in 20,536 high-risk individuals: a randomised placebo-controlled trial. Lancet. 2002;360: 7-22.

91. Sattar N, Preiss D, Murray HM, et al. Statins and risk of incident diabetes: a collaborative meta-analysis of randomised statin trials. Lancet. 2010;375:735-742.

92. Grundy SM. The issue of statin safety: where do we stand? Circulation. 2005;111:3016-3019.

93. Alsheikh-Ali AA, Ambrose MS, Kuvin JT, Karas RH. The safety of rosuvastatin as used in common clinical practice: a postmarketing analysis. Circulation. 2005;111:3051-3057.

94. Harris ML, Bron AJ, Brown NA, et al. Absence of effect of simvastatin on the progression of lens opacities in a randomised placebo controlled study. Oxford Cholesterol Study Group. Br J Ophthalmol. 1995;79: 996-1002.

95. Schlienger RG, Haefeli WE, Jick H, Meier CR. Risk of cataract in patients treated with statins. Arch Intern Med. 2001;161: 2021-2026.

96. Gaist D, Jeppesen U, Andersen M, Garcia Rodriguez LA, Hallas J, Sindrup SH. Statins and risk of polyneuropathy: a case-control study. Neurology. 2002;58:1333-1337.

97. Anderson JL, Muhlestein JB, Bair TL, et al. Do statins increase the risk of idiopathic polyneuropathy? Am J Cardiol. 2005;95: 1097-1099.

98. Muldoon MF, Ryan CM, Sereika SM, Flory JD, Manuck SB. Randomized trial of the effects of simvastatin on cognitive functioning in hypercholesterolemic adults. Am J Med. 2004;117:823-829.

99. Muldoon MF, Barger SD, Ryan CM, et al. Effects of lovastatin on cognitive function and psychological well-being. Am J Med. 2000;108: $538-546$.
Open Access Journal of Urology

\section{Publish your work in this journal}

The Open Access Journal of Urology is an international, peer-reviewed, open access journal publishing original research, reports, editorials, reviews and commentaries on all aspects of adult and pediatric urology in the clinic and laboratory including the following topics: Pathology, pathophysiology of urological disease; Investigation and treatment of

\section{Dovepress}

urological disease; Pharmacology of drugs used for the treatment of urological disease. The manuscript management system is completely online and includes a very quick and fair peer-review system, which is all easy to use. Visit http://www.dovepress.com/testimonials.php to read real quotes from published authors. 